\title{
With a disease for every day, who will care for the orphans?
}

\author{
Diane Kelsall MD MEd
}

$\mathrm{N}$ ovember is a busy month, and not just because of the lead-up to Christmas and other winter holidays, Remembrance Day or midterm examinations for many students. November has been transformed into an excuse for men to grow facial hair in support of men's health programs, as well as a time to pay attention to cardiopulmonary resuscitation, lung cancer, osteoporosis, Crohn disease and colitis, and Huntington disease. November hosts weeks highlighting pain, seniors' safety, addictions and lead poisoning prevention, in addition to a series of special days drawing international attention to pneumonia, chronic obstructive pulmonary diseases and diabetes. ${ }^{1,2}$ There are even 24 hours devoted to celebrating the invention of the toilet. ${ }^{3}$

Why are there so many days in recognition of diseases? The purposes vary from fundraising to promoting screening, but the organizers share a common desire to raise awareness and draw attention to their causes. This attention is particularly important for "orphan diseases" - those lifethreatening, debilitating or serious chronic conditions that affect only a very small number of people. ${ }^{4}$

Unfortunately, the accumulation of all of these special days may mean that some days pass largely unnoticed, while others are embraced by large segments of the population (Daffodil days and Movember come to mind). Which disease gets noticed may be down to the best marketing campaign, as some conditions are crowded out by others with bigger budgets or more curb appeal. A mechanism designed to raise awareness for mostly unknown disorders may instead become counterproductive, with orphan diseases orphaned yet again.

Patients with rare disorders and their families may feel isolated as they struggle for resources to deal with the consequences of their illnesses. Assistance with the high cost of related treatments requires acknowledgement by policy-makers; without recognition by funding agencies, it is unlikely that enough research will be directed into causes, therapies and that hoped-for cure. Even journals may inadvertently contribute to the isolation felt by these patients and families by choosing to publish articles on conditions that are more prevalent. And yet, although some diseases are rare in themselves, ${ }^{5}$ the large number of these conditions means that most physicians will have several patients with such a disorder in their practices.

Is it necessary for the people interested in these disorders to rely, perhaps in vain, on a special day, week or month for recognition? Not necessarily. Disease days aside, there is growing interest in rare disorders in Canada. With work on genomic projects, such as FORGE (Finding of Rare Disease Genes), we are beginning to understand the genetic basis for some of these conditions. Orphanet, an international reference portal for information on rare diseases, is now available in
Canada, with a national team providing information on Canadian specialized clinics, laboratories, research and patient organizations. In addition, the government of Canada is working on a new framework for the authorization of specific drugs, often expensive, used to treat orphan conditions. These initiatives and efforts by organizations such as the Canadian Organization for Rare Disorders mean that patients, their families and health care providers will have improved access to information and resources now, and that enhanced research programs may lead to a solid understanding of these disorders and clues to their future prevention and cure.

We think medical journals could be part of this endeavour. We are looking for articles on neglected conditions that may benefit from increased attention. We would like to highlight 1 or 2 of these conditions in the pages of CMAJ in the coming year. By "neglected," we mean that the condition is overlooked and that there is little awareness of it (which may mean that the disease is rare, but not necessarily). By "benefit," we mean that there must be good prospects of being able to do something positive about the condition through better use of existing treatments or services, or by pursuing a promising line of research. If you know about a suitable condition, please write to us at cmajeditorial@cmaj.ca, putting "neglected conditions" in the subject line of your email.

And perhaps, in the future, there will no longer be a need for so many disease days.

\section{References}

1. United Nations observances. New York (NY): United Nations. Available: www.un .org/en/events/observances/days.shtml (accessed 2013 Oct. 9).

2. Calendar of health promotion days. Ottawa (ON): Health Canada; 2013. Available: www.hc-sc.gc.ca/ahc-asc/calend/index-eng.php (accessed 2013 Oct. 9).

3. Cassels A. A new national holiday? My vote's for World Toilet Day. CMAJ 2010; 182:216.

4. Canada's orphan drug policy: learning from the best. Toronto (ON): Canadian Organization for Rare Disorders; 2005. Available: www.raredisorders.ca/documents /CanadaOrphanDPFinal.pdf (accessed 2013 Oct. 9).

5. Orphanet. Prevalence of rare diseases: bibliographic data. Orphanet Report Series June 2013; no. 1. Available: www.orpha.net/orphacom/cahiers/docs/GB/Prevalence _of_rare_diseases_by_alphabetical_list.pdf (accessed 2013 Oct. 9).

Competing interests: See www.cmaj.ca/site/misc/cmaj_staff.xhtml

Affiliation: Diane Kelsall is Deputy Editor, CMAJ.

Correspondence to: $C M A J$ editor, pubs@cmaj.ca

\section{CMAJ 2013. DOI:10.1503/cmaj.131553}

FORGE (www.genomebc.ca/portfolio/projects/health-projects /finding-of-rare-disease-genes-in-canada-forge-canada/)

Orphanet (www.orpha.net)

Canadian Organization for Rare Disorders (www.raredisorders.ca) 